\title{
A REDUÇÃO DO NÚMERO DE ESTABELECIMENTOS FAMILIARES E DO PESSOAL OCUPADO NA AGRICULTURA FAMILIAR: HIPÓTESES À LUZ DA ANÁLISE DOS CENSOS AGROPECUÁRIOS 2006 E $2017^{1}$
}

Alexandre Valadares ${ }^{2}$

Fábio Alves ${ }^{3}$

\section{INTRODUÇÃO: UM PANORAMA PRELIMINAR}

Os resultados do Censo Agropecuário 2017 revelaram algumas mudanças importantes no panorama da agricultura familiar no país em comparação com o cenário apresentado na pesquisa de 2006. Este estudo propóe observar um pouco mais de perto, a partir de uma abordagem descritiva, algumas variaçóes observadas no contingente de mão de obra ocupada nos estabelecimentos agropecuários familiares no período intercensitário.

De modo geral, a série histórica dos Censos Agropecuários mostra que o número de ocupados em estabelecimentos agropecuários - familiares e não familiares - começou a diminuir a partir de 1985, quando, vindo em trajetória ascendente desde os anos 1950, registrou seu ápice: 23,4 milhóes de trabalhadores. A partir de então, este número se reduz a 17,9 milhóes em 1995 , 16,7 milhões em 2006 e 15,1 milhóes em 2017. O número médio de pessoas ocupadas por estabelecimento também decresceu nas três décadas: de 4,03, em 1985, para 2,98, em 2017.

Este estudo, no entanto, pretende ater-se, fundamentalmente, à população ocupada de mais de 14 anos de idade nos estabelecimentos agropecuários. Os dados abertos e agregados do Sistema IBGE de Recuperação Automática (Sidra) permitem selecionar esse grupo etário apenas nos dados de pessoal ocupado disponíveis a partir do Censo 1995. O contingente total se reduz um pouco, mas a diferença dos totais entre os censos é menor: os ocupados de mais de 14 anos de idade em estabelecimentos agrícolas em 1995 e 2006 se igualam numericamente 15,49 e 15,50 milhões respectivamente -, mas, em 2017, este quantitativo sofre uma redução de $6 \%$, ficando em 14,52 milhóes de ocupados.

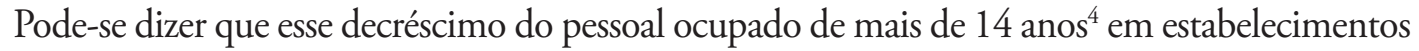
agropecuários entre os dois últimos Censos Agropecuários se deveu à diminuição do número de trabalhadores ocupados em estabelecimentos classificados como agricultura familiar. Os dados extraídos da plataforma Sidra/IBGE não permitem colher informaçôes sobre os ocupados por tipo de estabelecimento (familiar x não familiar) nos censos anteriores a 2006, de sorte que não é

\footnotetext{
1. DOI: http://dx.doi.org/10.38116/bmt70/nta1

2. Técnico de planejamento e pesquisa na Diretoria de Estudos e Políticas Sociais (Disoc) do Ipea.

3. Especialista em políticas públicas e gestão governamental em exercício na Disoc/lpea.

4. Daqui para frente, todas as referências a pessoal ocupado dizem respeito apenas aos ocupados acima de 14 anos de idade.
} 
possível, dentro desses limites, apontar se essa perda da mão de obra em unidades familiares resulta de uma tendência precedente, que acompanharia a linha geral de redução do total de ocupados em estabelecimentos agropecuários ao longo dos censos. No entanto, a comparação entre as variaçóes, quanto aos ocupados nos estabelecimentos não familiares e familiares, revela que a diminuição do número de trabalhadores nestes últimos pode não ser um efeito da redução gradativa e estrutural do total de pessoal ocupado em estabelecimentos agropecuários. Se, em 2006, havia 11,41 milhóes de trabalhadores ocupados em estabelecimentos familiares, em 2017 este número caiu a 9,67 milhóes, uma diminuição de 15\%. Em contrapartida, o número de ocupados em estabelecimentos classificados como não familiares subiu de 4,09 milhóes, em 2006, para 4,85 milhóes, em 2017, alta de 18\%.

Esses resultados sugerem que a redução da mão de obra dos estabelecimentos familiares pode estar relacionada a fatores intrínsecos ao grupamento agrícola familiar ou, ao menos, a fatores realçados nas mudanças ocorridas no panorama agrário do país, sob a perspectiva da agricultura familiar. A impossibilidade de, nesta etapa de pesquisa, acessar em tempo hábil os microdados do Censo Agropecuário não permite avançar para a construção estatística de relações de causalidade entre os fenômenos, mas é possível, com base numa análise descritiva, levantar algumas hipóteses que qualificam o tema. As seçôes seguintes dedicam-se a essa tarefa.

\section{MENOS ESTABELECIMENTOS, ÁREA MAIOR: OS DADOS FUNDIÁRIOS E A REDUÇÃO DO PESSOAL OCUPADO NA AGRICULTURA FAMILIAR}

Entre os Censos 2006 e 2017, verificou-se, em termos agregados, uma redução do número total de estabelecimentos da agricultura familiar de 4,37 milhôes para 3,90 milhóes, uma variação negativa de $11 \%$. No mesmo período, o número de estabelecimentos não familiares teve um incremento de $45 \%$, crescendo de 809,4 mil para 1,18 milhão.

No cômputo geral, as alterações resultaram em uma diminuição relativamente pequena do número total de estabelecimentos - de 5,17 milhóes para 5,07 milhóes, perda de 2\% -; contudo, no que concerne à extensão e à distribuição da área total dos estabelecimentos, a redução do número de unidades familiares e o aumento das não familiares acompanharam uma tendência concentradora no quadro fundiário do país. A área total abrangida pelos estabelecimentos agropecuários aumentou em 5\%, de 333,68 milhóes de hectares para 351,29 milhóes de hectares: dentro dessa variação, os estabelecimentos não familiares ganharam quase $7 \%$ de área, indo de 253,58 para 270,40 milhóes de hectares, ao passo que os familiares expandiram em $1 \%$ sua área total, variando de 80,10 para 80,89 milhóes de hectares.

Portanto, se, como visto anteriormente, a perda total de pessoal ocupado nos estabelecimentos agropecuários pode ser, em números agregados, explicada quase completamente pela redução da força de trabalho ocupada em unidades familiares, aqui se observa que, do total de 17,61 milhôes de hectares acrescidos à área total dos estabelecimentos agropecuários entre os censos, os não familiares se apropriaram de $95 \%$.

Por outro ângulo, uma vez que o número de estabelecimentos familiares se reduziu em $11 \%$, mas a área total desses estabelecimentos se manteve praticamente inalterada em relação aos resultados de 2006 - em torno de 80 milhóes de hectares, pode-se distinguir, aqui, uma primeira explicação para a redução do total de ocupados na agricultura familiar entre os dois 
censos. Dito de outro modo, a redução do total de estabelecimentos familiares explica em parte a redução do total de pessoas ocupadas na agricultura familiar. $\mathrm{O}$ fato de que o número médio de trabalhadores ocupados por estabelecimento agrícola familiar praticamente não se tenha alterado entre os censos - 2,6, em 2006, e 2,5, em 2017 - reforça essa possibilidade. De outra parte, o aumento significativo da área média (em hectares) por trabalhador na agricultura $-7,0$ ha por pessoa ocupada, em 2006, para 8,4 ha por pessoa ocupada, em 2017 - permite cogitar que a redução de ocupados em estabelecimentos agrícolas familiares pode estar relacionada, também, ao aumento de maquinário e insumos na produção agrícola familiar. ${ }^{5}$

Antes, porém, convém analisar dois aspectos: primeiramente, em que medida a variação do total de ocupados na agricultura familiar pode estar relacionada com a distribuição dos estabelecimentos familiares por grupos de área; em segundo lugar, em que medida a variação do número de ocupados na agricultura familiar acompanhou as mudanças no quadro fundiário por região. Estes tópicos são tratados nas subseçôes seguintes.

\subsection{Menores estabelecimentos ocupam mais, mas com menor participação da agricultura familiar}

Os gráficos 1 e 2 mostram a distribuiçấo dos estabelecimentos agropecuários - total e agricultura familiar -, por grupos de área, para 2006 e 2017, considerando o número dos estabelecimentos (gráfico 1) e a área dos estabelecimentos (gráfico 2).

\section{GRÁFICO 1}

Número de estabelecimentos por grupos de área - Brasil (2006 e 2017)

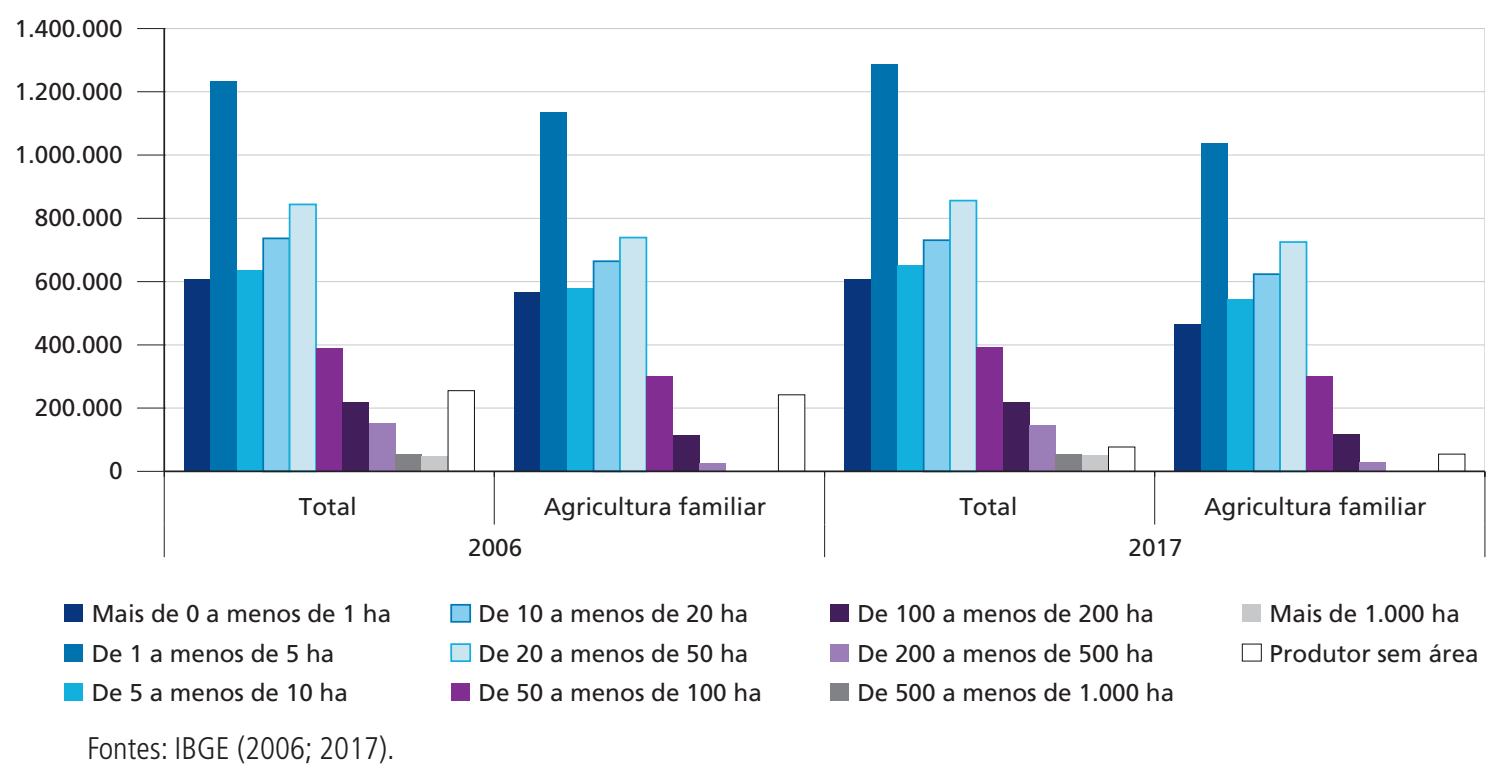

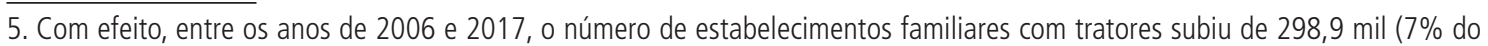
total) para 446,6 mil (11\% do total). Da mesma forma, o total de estabelecimentos familiares que declaram usar agrotóxicos subiu de 1,27 milhão ( $29 \%$ do total) para 1,39 milhão (36\% do total). No entanto, uma investigação mais detalhada da relação entre a mecanização e o uso de insumos químicos - tecnologias poupadoras de trabalho humano - com a redução do pessoal ocupado na agricultura familiar excederia o escopo deste estudo. 
GRÁFICO 2

Área de estabelecimentos, por grupos de área - Brasil (2006 e 2017)

(Em milhões)

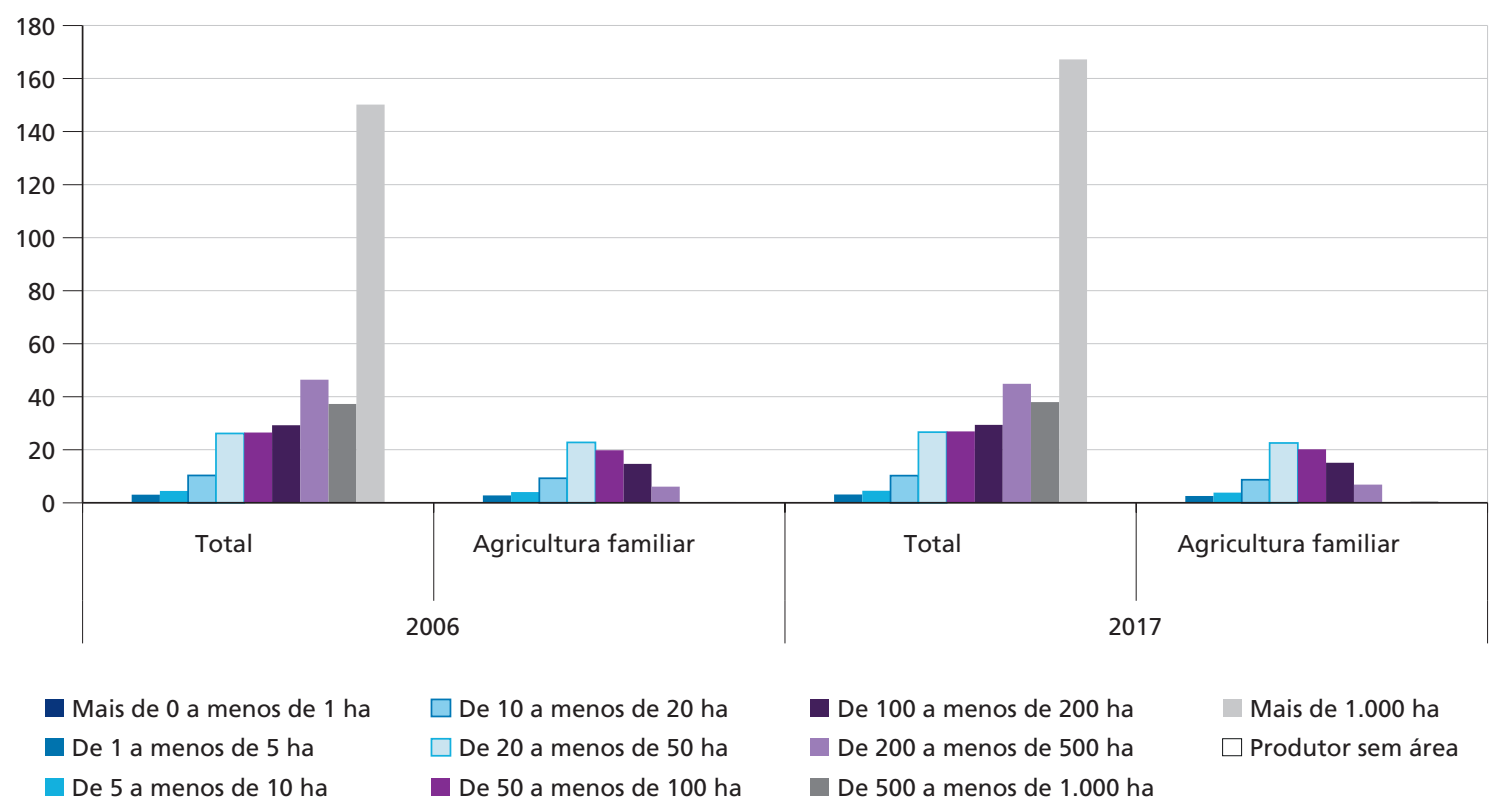

Fontes: IBGE (2006; 2017).

A primeira conclusão que ressalta da leitura comparada dos gráficos é que, conforme se apontou anteriormente, o crescimento total da área dos estabelecimentos se deu pelo agravamento da concentração da propriedade da terra, que segue sendo o traço mais distorcivo - destacado na barra alta do gráfico 2 - da estrutura fundiária brasileira: os estabelecimentos com mais de 1.000 ha, embora sigam representando $1 \%$ do número total, dominam $48 \%$ de toda a área dos estabelecimentos, cobrindo 167,2 milhóes de hectares: isto significa que um quinto de todo o território brasileiro (urbano ou rural) está dentro de pouco mais de 51 mil estabelecimentos agropecuários (segundo o Censo 2017) com mais de 1.000 ha. A segunda conclusão que os gráficos inspiram é que o quadro fundiário, visto a partir da perspectiva da distribuição dos estabelecimentos, em número e área, entre grupos de área, variou muito pouco entre os anos de 2006 e 2017: tanto no que diz respeito ao conjunto total dos estabelecimentos quanto no que concerne ao segmento da agricultura familiar, as variaçóes não alteraram significativamente a ordem das proporçôes dentro de cada um desses universos.

Mas, embora a distribuição dos estabelecimentos por grupos de área, em número de unidades e em área total, dentro do universo da agricultura familiar, praticamente não tenha sofrido mudanças, a participação relativa dos estabelecimentos familiares nos totais por grupos de área teve perdas significativas, que se mostraram maiores justamente nos estratos de menor área. A tabela 1 mostra esses dois aspectos. 


\section{TABELA 1}

Proporção de número e área de estabelecimentos, total e agricultura familiar, e participação da agricultura familiar sobre total, por grupos de área - Brasil (2006 e 2017) (Em \%)

\begin{tabular}{|c|c|c|c|c|c|c|c|c|c|c|c|c|}
\hline \multirow{3}{*}{$\begin{array}{l}\text { Grupos } \\
\text { de área }\end{array}$} & \multicolumn{6}{|c|}{ Número de estabelecimentos } & \multicolumn{6}{|c|}{ Área dos estabelecimentos } \\
\hline & \multicolumn{3}{|c|}{2006} & \multicolumn{3}{|c|}{2017} & \multicolumn{3}{|c|}{2006} & \multicolumn{3}{|c|}{2017} \\
\hline & Total & $\begin{array}{c}\text { Agri- } \\
\text { cultura } \\
\text { familiar }^{1}\end{array}$ & $\begin{array}{c}\text { Agricultura } \\
\text { familiar/ } \\
\text { total }\end{array}$ & Total1 & $\begin{array}{l}\text { Agricultura } \\
\text { familiar }^{1}\end{array}$ & $\begin{array}{c}\text { Agricultura } \\
\text { familiar/ } \\
\text { total }\end{array}$ & Total' ${ }^{1}$ & $\begin{array}{l}\text { Agricultura } \\
\text { familiar }^{1}\end{array}$ & $\begin{array}{c}\text { Agricultura } \\
\text { familiar/ } \\
\text { total }\end{array}$ & Total' ${ }^{1}$ & $\begin{array}{l}\text { Agricultura } \\
\text { familiar }^{1}\end{array}$ & $\begin{array}{c}\text { Agricultura } \\
\text { familiar/ } \\
\text { total }\end{array}$ \\
\hline $\begin{array}{l}\text { Mais de } 0 \\
\text { a menos } \\
\text { de } 1 \text { ha }\end{array}$ & 11,70 & 13,00 & $93,50^{2}$ & 12,00 & 12,00 & $76,90^{2}$ & 0,10 & 0,30 & $92,90^{2}$ & 0,10 & 0,30 & $77,80^{2}$ \\
\hline $\begin{array}{l}\text { De } 1 \text { a } \\
\text { menos de } \\
5 \text { ha }\end{array}$ & 23,80 & 26,00 & $91,90^{2}$ & 25,40 & 26,60 & $80,60^{2}$ & 0,90 & 3,50 & $91,70^{2}$ & 0,90 & 3,20 & $81,20^{2}$ \\
\hline $\begin{array}{l}\text { De } 5 \text { a } \\
\text { menos } \\
\text { de } 10 \text { ha }\end{array}$ & 12,30 & 13,20 & $90,80^{2}$ & 12,80 & 14,00 & $83,80^{2}$ & 1,30 & 5,10 & $90,80^{2}$ & 1,30 & 4,70 & $83,90^{2}$ \\
\hline $\begin{array}{l}\text { De } 10 \text { a } \\
\text { menos } \\
\text { e } 20 \text { ha }\end{array}$ & 14,20 & 15,20 & 90,20 & 14,40 & 16,00 & 85,30 & 3,10 & 11,60 & 90,00 & 2,90 & 10,80 & 85,40 \\
\hline $\begin{array}{l}\text { De } 20 \text { a } \\
\text { menos } \\
\text { de } 50 \text { ha }\end{array}$ & 16,30 & 16,90 & 87,60 & 16,90 & 18,60 & 84,70 & 7,80 & 28,40 & 87,10 & 7,60 & 27,80 & 84,50 \\
\hline $\begin{array}{l}\text { De } 50 \text { a } \\
\text { menos } \\
\text { de } 100 \text { ha }\end{array}$ & 7,60 & 6,90 & 76,70 & 7,80 & 7,70 & 76,30 & 7,90 & 24,80 & 74,90 & 7,70 & 24,90 & 74,90 \\
\hline $\begin{array}{l}\text { De } 100 \text { a } \\
\text { menos } \\
\text { de } 200 \text { ha }\end{array}$ & 4,20 & 2,70 & 52,80 & 4,30 & 3,00 & 53,60 & 8,80 & 18,30 & 50,20 & 8,40 & 18,60 & 51,30 \\
\hline $\begin{array}{l}\text { De } 200 \text { a } \\
\text { menos de } \\
500 \text { ha }\end{array}$ & 2,90 & 0,60 & 16,70 & 2,90 & 0,70 & 19,00 & 13,90 & 7,60 & 13,10 & 12,80 & 8,50 & 15,20 \\
\hline $\begin{array}{l}\text { De } 500 \text { a } \\
\text { menos de } \\
1.000 \text { ha }\end{array}$ & 1,00 & 0,00 & 0,30 & 1,10 & 0,00 & 0,80 & 11,20 & 0,10 & 0,30 & 10,80 & 0,30 & 0,70 \\
\hline $\begin{array}{l}\text { Mais de } \\
1.000 \text { ha }\end{array}$ & 0,90 & 0,00 & 0,20 & 1,00 & 0,00 & 0,40 & 45,00 & 0,40 & 0,20 & 47,60 & 0,90 & 0,40 \\
\hline $\begin{array}{l}\text { Produtor } \\
\text { sem área }\end{array}$ & 4,90 & $5,50^{2}$ & $94,90^{2}$ & 1,50 & $1,40^{2}$ & $70,60^{2}$ & 0,00 & 0,00 & 0,00 & 0,00 & 0,00 & 0,00 \\
\hline Total & 100 & 100 & 84,40 & 100 & 100 & 76,80 & 100 & 100 & 24,00 & 100 & 100 & 23,00 \\
\hline
\end{tabular}

Fontes: IBGE (2006; 2017).

Notas: "Nestas colunas, pode-se ver a estabilidade "estrutural" - de 2006 para 2017 - da distribuição dos estabelecimentos por grupos de área, tanto no universo total quanto no universo específico da agricultura familiar.

${ }^{2}$ Estes dados denotam a redução da participação dos estabelecimentos familiares sobre os estabelecimentos totais nos estratos menores de área.

Ainda, com base nos dados realçados em itálico, vê-se uma redução bastante acentuada dos estabelecimentos de "produtores sem área": eles representavam 5,5\% do total dos familiares em 2006, mas passaram a 1,4\% em 2017, e a participação da agricultura familiar neste segmento 
reduziu-se de quase $95 \%$ a $71 \%$. Os dados absolutos oferecem uma ilustração mais expressiva dessa diminuição: em 2006, havia 255 mil produtores sem área, dos quais 242 mil eram familiares; em 2017, esses valores caíram, respectivamente, a 77 mil e 54 mil. Ou seja: apenas na classe dos produtores sem área, a agricultura familiar perdeu 188 mil estabelecimentos. Considerando-se que, entre os censos, a agricultura familiar "perdeu" cerca de 469 mil estabelecimentos, apenas a variação negativa entre produtores familiares sem área equivaleria, grosso modo, a 40\% da redução da agricultura familiar. Esta redução terá, consequentemente, impacto sobre a redução do pessoal ocupado na agricultura familiar, uma vez que esse dado acompanha o dado de total de estabelecimentos.

No entanto, essa perda parece decorrer antes de uma mudança metodológica na coleta da informação que propriamente de uma alteração no panorama da realidade agrária: no levantamento de 2006 (IBGE, 2017, p. 10-11, grifos nossos), uma vez

identificada a existência de atividade de criação/produção agropecuária de pessoal empregado no mesmo estabelecimento, em área sujeita à administração do produtor/proprietário, toda aquela produção foi considerada como parte do estabelecimento, e todos os dados colhidos integraram o único questionário aplicado ao estabelecimento. Caso tenha sido informado que a administração da referida criação/produção não esteve sob responsabilidade do produtor, um novo questionário foi aberto para o empregado, como se fosse um novo estabelecimento agropecuário, sendo nele registradas todas as características referentes e seus respectivos quantitativos, aplicando-se todos os parâmetros da pesquisa, e este produtor empregado foi considerado como um "produtor sem área". Tal procedimento trouxe como consequência o incremento no número de estabelecimentos de produtores sem área em relação aos censos anteriores.

Contudo, para o Censo 2017 (IBGE, 2017, p. 11, grifos nossos), “não se abriu questionário para esse produtor empregado/morador, e toda a produção/criação referida a esta condição integrou o questionário do estabelecimento agropecuário”.

Em síntese, no Censo 2006, quando se identificava um empregado com produção própria na área do proprietário/empregador, a este empregado era imputado um estabelecimento agropecuário "independente". Este procedimento "inflou” o quantitativo de estabelecimentos familiares na pesquisa desse ano. Uma vez que os agricultores familiares representavam, naquele ano, 95\% dos "produtores sem área", a retificação metodológica de 2017 acabou impactando negativamente o número total de estabelecimentos familiares: como, de resto, os "produtores sem área" não têm área, essa redução não teve impacto sobre a área total da agricultura familiar no Censo 2017, o que, em parte, ajuda a explicar por que a área total dos estabelecimentos familiares quase náo se alterou, a despeito da queda do número de estabelecimentos.

Com efeito, a perda total de 469 mil estabelecimentos familiares entre os censos é o "saldo negativo" referente a uma diminuição de 287 mil estabelecimentos familiares de até 50 ha (com as unidades familiares de menos de 10 ha representando $80 \%$ desta diminuição), mais a redução de 188 mil estabelecimentos familiares de "produtores sem área", com uma pequena compensação dada pelo crescimento de pouco mais de 5 mil unidades familiares com mais de 
50 ha. ${ }^{6}$ Grosso modo, a perda de unidades familiares com menos de 10 ha explicaria metade da redução do número de estabelecimentos familiares, a perda de "produtores familiares sem área” responderia por $40 \%$ dessa redução (como se viu anteriormente), e os 10\% restantes tocariam às unidades familiares com mais de 10 ha e menos de 50 ha.

O gráfico 3 mostra como essa queda dos estabelecimentos familiares pequenos e de produtores sem área repercutiu na redução do pessoal ocupado na agricultura familiar como um todo.

\section{GRÁFICO 3}

Pessoal ocupado por grupos de área e tipologia do estabelecimento - Brasil (2006 e 2017)

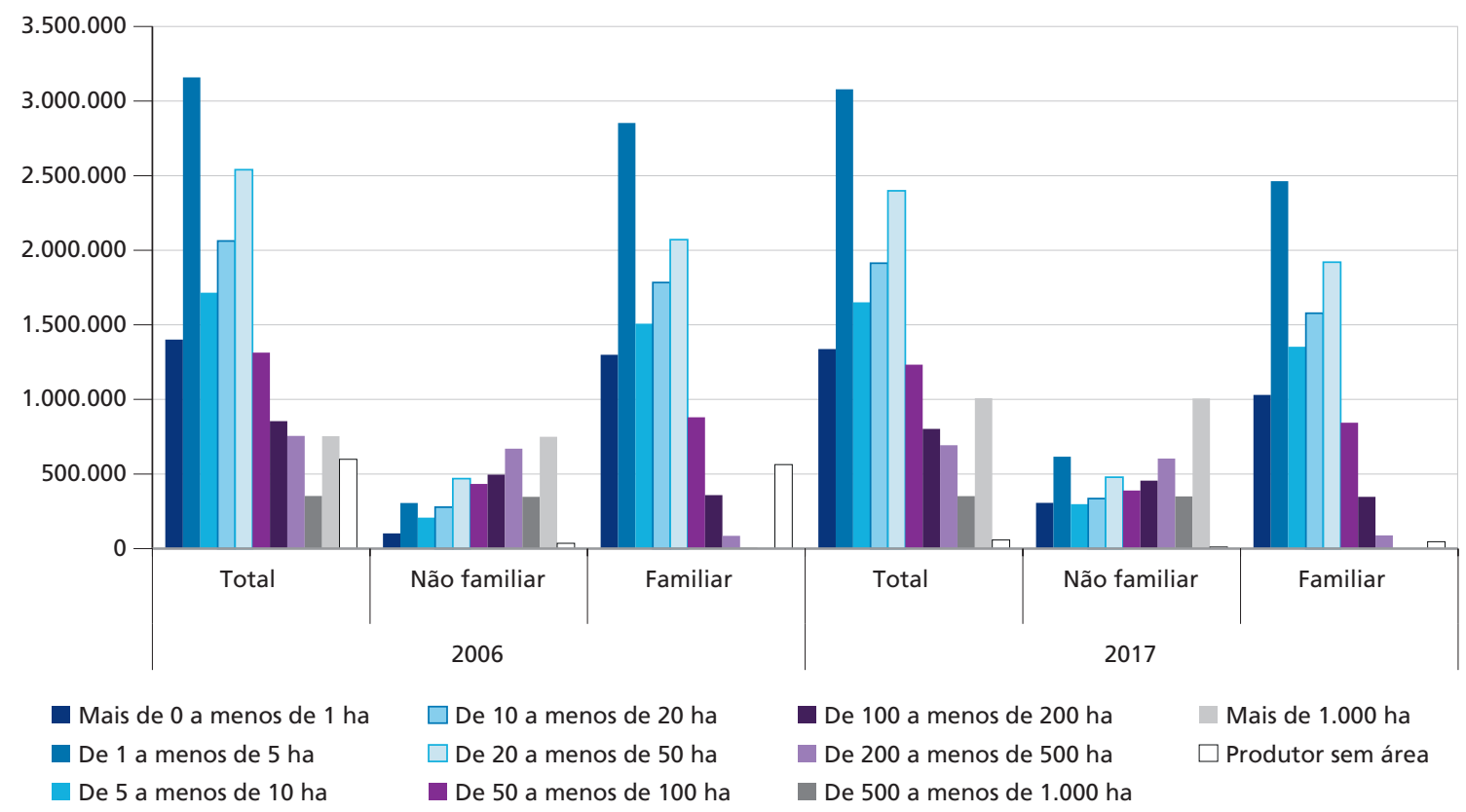

Fontes: IBGE (2006; 2017).

Em relação ao total, entre 2006 e 2017, houve pouca alteração quanto à distribuição do pessoal ocupado por grupos de área. Duas exceçóes despontam na comparação entre os anos considerados: o aumento de ocupados em estabelecimentos acima de 1.000 ha (inteiramente devido ao aumento de ocupados nessa faixa de área em estabelecimentos patronais) e a redução bastante acentuada do pessoal ocupado em estabelecimentos do tipo "produtor sem área", devida, quase em sua totalidade, à mudança metodológica indicada anteriormente. De resto, a estrutura de distribuição dos ocupados em estabelecimentos agropecuários por grupos de área segue o mesmo padrão em 2006 e 2017, como as proporçôes na tabela 2 confirmam.

6. Um dado que condiz com o crescimento da agricultura familiar no Norte e no Centro-Oeste, onde os módulos fiscais são maiores e, portanto, enquadram estabelecimentos de maior área na agricultura familiar, como se verá depois. 
TABELA 2

Pessoal ocupado em estabelecimentos por grupos de área - Brasil (2006 e 2017)

\begin{tabular}{lrrrr}
\hline Grupos de área & 2006 & $\%$ & 2017 & $\%$ \\
\hline Mais de 0 a menos de 1 ha & 1.401 .008 & 9,0 & 1.337 .523 & 9,2 \\
De 1 a menos de 5 ha & 3.158 .712 & 20,4 & 3.078 .891 & 21,2 \\
De 5 a menos de 10 ha & 1.715 .559 & 11,1 & 1.650 .821 & 11,4 \\
De 10 a menos de 20 ha & 2.061 .904 & 13,3 & 1.912 .950 & 13,2 \\
De 20 a menos de 50 ha & 2.539 .975 & 16,4 & 2.399 .015 & 16,5 \\
De 50 a menos de 100 ha & 1.313 .409 & 8,5 & 1.233 .011 & 8,5 \\
De 100 a menos de 200 ha & 854.028 & 5,5 & 802.655 & 5,5 \\
De 200 a menos de 500 ha & 755.744 & 4,9 & 692.542 & 4,8 \\
De 500 a menos de 1.000 ha & 353.061 & 2,3 & 351.910 & 2,4 \\
Mais de 1.000 ha & 753.340 & 4,9 & 1.007 .839 & 6,9 \\
Produtor sem área & 599.159 & 3,9 & 57.916 & 0,4 \\
Total & 15.505 .899 & 100,0 & 14.525 .073 & 100,0 \\
\hline
\end{tabular}

Fontes: IBGE (2006; 2017).

Por outro lado, o gráfico 3 ilustra claramente a redução de pessoal ocupado na agricultura familiar até os estabelecimentos familiares com menos de 50 ha, mas com perdas mais acentuadas nos grupos de área inferiores a 20 ha. Os estabelecimentos familiares com menos de 5 ha, que ocupavam 4,15 milhóes de pessoas em 2006, passaram a ocupar 3,49 milhóes em 2017, uma queda de $16 \%$ ou de 660 mil ocupados, aproximadamente. As unidades familiares entre 5 ha e 20 ha sofreram uma redução de $11 \%$, saindo de 3,29 milhóes para 2,93 milhôes de ocupados - 361 mil a menos. E, mais significativo, o total de ocupados em estabelecimentos familiares do tipo "produtor sem área" tombou de 563,1 mil para 46,7 mil, nada menos que $92 \%$ a menos. Considerando que os estabelecimentos familiares perderam pessoal ocupado em praticamente todos os grupos de área, ${ }^{7}$ pode-se afirmar, da perda total de 1,74 milhão de ocupados que a agricultura familiar sofreu entre 2006 e 2017, 38\% são devidos à redução de ocupados em unidades familiares de até 5 ha; 30\%, à redução de ocupados em unidades familiares de "produtor sem área"; $21 \%$, à redução de ocupados em unidades familiares entre 5 e 20 ha; e os $11 \%$ restantes, nas demais faixas de área.

Em síntese, a perda de pessoal ocupado na agricultura familiar acompanha o padrão da redução do número de estabelecimentos familiares por grupos de área, e incide muito mais fortemente nos estabelecimentos situados nos menores estratos de área.

No entanto, observando, ainda, o gráfico 3, nota-se que, entre os estabelecimentos não familiares, além do crescimento de trabalhadores nas unidades com mais de 1.000 ha, aumentou - consideravelmente - o número de ocupados naquelas com menos de 20 ha, sobretudo naqueles com menos de 5 ha. No grupo de estabelecimentos náo familiares com

7. À exceção do pequeno acréscimo de 3,3 mil na faixa de 200 ha a menos de 500 ha. 
menos de 5 ha, o total de pessoas ocupadas mais que dobrou, passando de 407,0 mil para 923,1 mil entre 2006 e 2017; somando este resultado à variação total das pessoas ocupadas nos estabelecimentos não familiares de até 20 ha, o ganho total foi de $75 \%-663,5$ mil a mais - de trabalhadores entre 2006 e 2017.

Não obstante, tendo em conta o total dos estabelecimentos agropecuários, as unidades de até 20 ha respondem por mais da metade dos ocupados - 54\% em 2006 e 55\% em 2017 e, dentro desse grupo, as unidades familiares seguem respondendo pela grande maioria dos ocupados, apesar das perdas: nada menos que $44 \%$ (6,4 milhôes) de todos os ocupados em estabelecimentos agropecuários em 2017 (14,5 milhões) trabalhavam em unidades familiares de menos de 20 ha. Contudo, como esses dados mostraram, a maior parte da perda de ocupados em estabelecimentos familiares, de 2006 para 2017, ocorreu em estabelecimentos de até 20 ha, a mesma faixa de área que, entre os não familiares, registrou maior aumento de pessoal ocupado - chegando a 1,6 milháo em 2017.

Uma vez que a distribuição do pessoal ocupado por grupos de área (conforme a tabela 2) se manteve praticamente a mesma entre os censos, os indícios autorizam a formulação de três hipóteses, descritas a seguir.

1) A perda do número de estabelecimentos familiares e a redução do pessoal ocupado na agricultura familiar, que a acompanha, foram mais intensas nos estabelecimentos de menor área (até 20 ha).

2) Dado que não houve variação significativa nas proporções da estrutura de distribuição do número de estabelecimentos e do total de pessoal ocupado por grupos de área, a perda de unidades familiares e o aumento de unidades não familiares na faixa de até 20 ha (na qual incidem mais fortemente tais mudanças) poderia corresponder a um processo de conversão sem concentração, isto é, de conversão das unidades familiares em patronais sem necessariamente o reagrupamento daquelas em estabelecimentos maiores.

3) Considerando que a classificação de um estabelecimento como "familiar" envolve, nos termos da Lei no 11.326/2006, quatro critérios - o tamanho da área (no máximo de quatro módulos fiscais), a utilização predominante de mão de obra familiar, o exercício da direção do estabelecimento com a família e a renda familiar originada predominantemente da atividade do estabelecimento -, é possível que fatores conjunturais ocorridos entre 2006 e 2017 tenham afetado um ou mais desses quesitos, fazendo que muitos dos estabelecimentos das faixas menores de área deixassem de ser classificados como unidades familiares.

Dos quatro parâmetros básicos utilizados no censo para classificar os estabelecimentos como familiares, dois estão relacionados a características intrínsecas à atividade agrícola familiar: a direção do estabelecimento realizada pela família e o trabalho predominantemente familiar. Quanto aos demais, ou têm a função de delimitar o universo da pequena propriedade rural (no caso, o limite máximo de quatro módulos fiscais), ou de determinar a finalidade agrícola dos estabelecimentos (no caso, a renda predominantemente advinda do estabelecimento). Este último quesito em particular é problemático sobretudo para os pequenos estabelecimentos familiares, grande parte compostos por minifúndios em que a família tem, por estratégia de sobrevivência, a complementação da renda 
por atividades externas ao estabelecimento. Uma quebra de safra, por exemplo, pode aumentar o peso das rendas externas em relação ao que foi aferido dentro da propriedade, o que náo implica mudança da característica do estabelecimento. Por outro lado, com relação à composição da mão de obra, o aumento do pessoal contratado dentro do estabelecimento a ponto de sobrepor em número o trabalho familiar concede ao estabelecimento características patronais.

Com efeito, dado que o módulo fiscal no Brasil varia de 5 ha a 110 ha, a condição de tamanho de área, como critério de classificação da agricultura familiar, é respeitada por todos os estabelecimentos de até 20 ha, de sorte que, nesse caso, a mudança de classificação de estabelecimentos familiares em não familiares não pode ser diretamente atribuída à concentração fundiária. Por outro lado, os parâmetros relativos ao predomínio do uso da mão de obra familiar e ao predomínio da renda oriunda das atividades realizadas no estabelecimento sobre a renda total não podem ser aferidos senão por tabulaçóes especiais. ${ }^{8} \mathrm{O}$ que se pode adiantar, aqui, é que provavelmente esses dois critérios - proporção da mão de obra familiar e proporção da renda auferida pela atividade agropecuária no estabelecimento - determinaram a mudança de classificação de estabelecimentos familiares em não familiares: definir em que medida cada um deles contribuiu para tal mudança é uma tarefa que ficará para outra etapa de pesquisa. ${ }^{9}$

\subsection{Pessoal ocupado, segundo laços de parentesco: uma composição um pouco menos familiar da mão de obra dos estabelecimentos agropecuários}

Embora apenas marginalmente, os dados referentes à composição, segundo laços de parentesco com o produtor, do pessoal ocupado em estabelecimentos, para os anos de 2006 e 2017, apontam, em certa medida, na mesma direçáo das colocaçóes alinhavadas anteriormente. Sob essa perspectiva, pode-se constatar que a perda de pessoal ocupado nos estabelecimentos agropecuários como um todo se deu, fundamentalmente, entre ocupados com laços de parentesco com o produtor e entre produtores sem área e estabelecimentos pequenos.

Com efeito, em 2006, havia 11,8 milhóes de ocupados com laços de parentesco com o produtor nos estabelecimentos agropecuários; em 2017, esse total se reduziu a 10,6 milhóes; em contrapartida, o pessoal ocupado sem laços de parentesco com o produtor aumentou de 3,7 milhóes para 3,9 milhóes.

Naturalmente, as perdas maiores de pessoal ocupado com laços de parentesco se deu entre os produtores sem área, em virtude da mudança metodológica já indicada: eles respondem por $42 \%$ dessa redução. Os estabelecimentos menores, de até 20 ha, respondem por 33\% dela.

8. Embora a Lei ํo 12.512/2011 tenha modificado a redação da Lei ㄲo 11.326/2006, estabelecendo que, para ser considerado familiar, um produtor deveria auferir um "percentual mínimo da renda familiar" - pendente de regulamentação - de atividades do seu estabelecimento, a metodologia adotada no Censo 2017 leva em consideração o critério anterior, segundo o qual, para ser caracterizado como familiar, um estabelecimento deve ter a maior parte de sua renda decorrente das atividades agropecuárias realizadas pela família. Tal critério favorece a comparabilidade entre os dados de 2017 e 2006 e está, ademais, de acordo com o Decreto № 9.064/2017, que caracteriza as unidades familiares de produção agrária, também, pela predominância da renda oriunda das atividades produtivas do estabelecimento. Com isso, a renda pode ter sido um critério decisivo na mudança de classificação das unidades familiares em não familiares. Para a verificação do parâmetro metodológico adotado no Censo 2017, ver DelGrossi (2019).

9. Um estudo próximo vai debruçar-se exatamente sobre essa questão. 
Em suma, essas duas classes de estabelecimentos são responsáveis, juntas, em termos absolutos, por três quartos da perda de pessoal ocupado com laços de parentesco nos estabelecimentos agropecuários.

O gráfico 4 exibe os resultados comparados dos anos 2006 e 2017 para ocupados com e sem laços de parentesco com o produtor. Além da homologia estrutural da distribuição de ocupados, com e sem laço de parentesco com o produtor, entre 2006 e 2017, dois dados chamam a atenção. Primeiramente, o fato de que, apesar das perdas, a grande maioria dos ocupados em estabelecimentos agropecuários como um todo trabalha em estabelecimentos pequenos: quase metade (47\%) de todos os ocupados trabalha em unidades agropecuárias de menos de 20 ha e tem laços de parentesco com o produtor - com destaque para o grupo de estabelecimentos entre 1 ha e 5 ha, no qual o total de ocupados com laços de parentesco com o produtor chega a 2,7 milhóes.

\section{GRÁFICO 4}

Pessoal ocupado, por grupos de área e laço de parentesco com o produtor - Brasil (2006 e 2017)

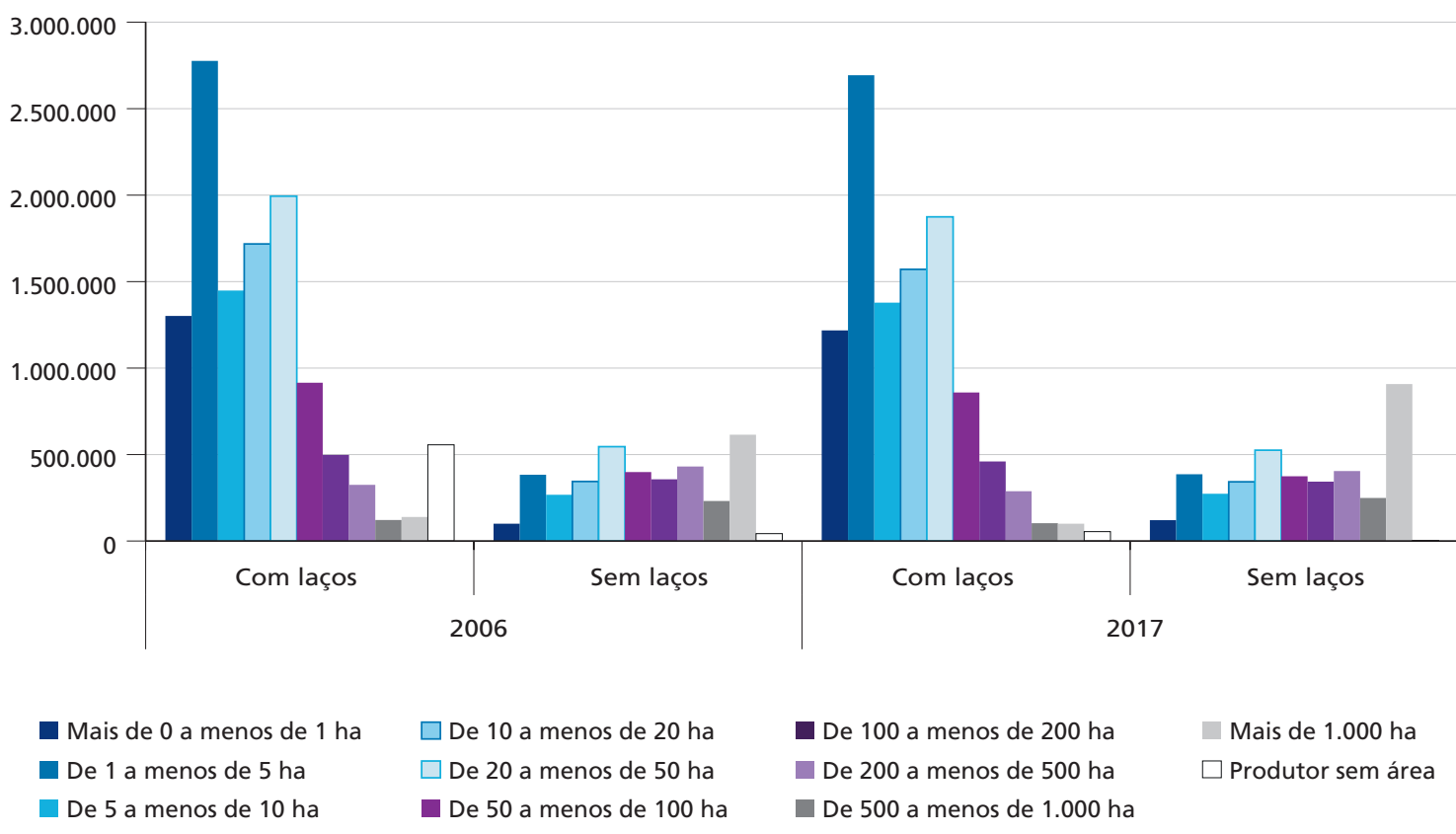

Fontes: IBGE (2006; 2017).

Em segundo lugar, o fato de que, entre o pessoal ocupado sem laços de parentesco com o produtor, os estabelecimentos com mais de 1.000 ha registraram o maior aumento de 2006 a 2017, saltando de 614,1 mil para 907,4 mil trabalhadores. É bastante provável que uma parte significativa do "desfalque" dos ocupados em estabelecimentos do tipo "produtores sem área”, com e sem laços de parentesco com o produtor, em 2006, tenha sido absorvida - ou tenha passado a ser computada - como ocupados sem laços de parentesco com o produtor em estabelecimentos com mais de 1.000 ha. Em síntese, os "produtores sem área” e os parentes 
que trabalhavam sob sua direção numa parte de área de um grande estabelecimento patronal, em 2006, passaram a ser considerados, todos, como pessoal ocupado sem laços de parentesco com o produtor/proprietário daquele estabelecimento patronal.

Por outro lado, a composição de mão de obra, por laços de parentesco, na agricultura familiar se manteve estável: em 2006, 88,8\% dos ocupados em unidades familiares tinham laços de parentesco com o produtor; em 2017, 87,1\%. Essa estabilidade é esperada, uma vez que a composição familiar da mão de obra é, precisamente, uma categoria definidora do caráter familiar de um estabelecimento agropecuário, isto é, se trata antes de uma característica intrínseca ao universo que de uma variável. Deste modo, tal como tem sido discutido até aqui, as variaçóes do total de pessoal ocupado na agricultura familiar respondem muito mais à variação do número de estabelecimentos familiares que a mudanças internas na composição da mão de obra da agricultura familiar.

Para adicionar outra perspectiva analítica ao quadro, cabe verificar, agora, como se processou a perda de pessoal ocupado na agricultura familiar por Grandes Regióes.

\subsection{A redução de pessoal ocupado na agricultura familiar no Nordeste e no Sul}

Em linhas gerais, a agricultura familiar encolheu, em número de estabelecimentos, área e pessoal ocupado, nas duas regiôes de economia agrícola historicamente mais tradicionais - o Nordeste e o Sul -, e se expandiu, ainda que sem compensar essa diminuiçáo, nas regiôes de fronteira agrícola ou de ocupação mais intensiva nas décadas recentes - Norte e Centro-Oeste.

A tabela 3 oferece um panorama no que diz respeito às perdas em número e área. Como se vê, as regióes Norte e Centro-Oeste registraram aumento de número e área dos estabelecimentos familiares: no Norte, eles cresceram 16\% em número e 19\% em área; no Centro-Oeste, 3\% e 7\%, respectivamente. Cabe, todavia, notar que, nessas regiôes, a agricultura não familiar cresceu ainda mais em número - 59\% no Norte e $23 \%$ no Centro Oeste -, embora tenha aumentado proporcionalmente menos em área - 17\% no Norte e 6\% no Centro-Oeste. Isto aponta para uma expansão de estabelecimentos não familiares de área média menor em comparação com dados de 2006. Apenas a título de exercício, calculando-se a diferença entre o número de unidades não familiares em 2017 e em 2006 e a diferença entre a área dessas unidades de 2017 e de 2006, pode-se dizer que a área média das unidades não familiares acrescidas ao "estoque" foi de 176,6 ha no Norte e 256,6 ha no Centro-Oeste: com isso, a área média do total desses estabelecimentos caiu de 616,7 para 454,3 ha, no Norte, e de 955,4 para 823,0 ha, no Centro-Oeste. 
TABELA 3

Número e área de estabelecimentos agropecuários, por tipologia - Brasil e Grandes Regiões (2006 e 2017)

\begin{tabular}{|c|c|c|c|c|c|c|c|c|c|c|c|c|}
\hline \multirow{3}{*}{$\begin{array}{l}\text { Brasil e } \\
\text { Grandes } \\
\text { Regiões }\end{array}$} & \multicolumn{6}{|c|}{ Número de estabelecimentos } & \multicolumn{6}{|c|}{ Área de estabelecimentos (ha) } \\
\hline & \multicolumn{3}{|c|}{ Familiar } & \multicolumn{3}{|c|}{ Não familiar } & \multicolumn{3}{|c|}{ Familiar } & \multicolumn{3}{|c|}{ Não familiar } \\
\hline & 2006 & 2017 & $\begin{array}{c}\text { Variação } \\
(\%)\end{array}$ & 2006 & 2017 & $\begin{array}{c}\text { Variação } \\
(\%)\end{array}$ & 2006 & 2017 & $\begin{array}{c}\text { Variação } \\
(\%)\end{array}$ & 2006 & 2017 & $\begin{array}{c}\text { Variação } \\
(\%)\end{array}$ \\
\hline Brasil & 4.366 .267 & 3.897 .408 & -11 & 809.369 & 1.175 .916 & 45 & 80.102 .694 & 80.891 .084 & 1 & 253.577 .343 & 270.398 .732 & 7 \\
\hline Norte & 412.666 & 480.575 & 16 & 63.112 & 100.038 & 59 & 16.611.277 & 19.767.199 & 19 & 38.924 .487 & 45.446 .150 & 17 \\
\hline Nordeste & 2.187 .131 & 1.838 .846 & -16 & 266.929 & 483.873 & 81 & 28.315 .052 & 25.925 .743 & -8 & 47.759 .359 & 44.968 .122 & -6 \\
\hline Sudeste & 699.755 & 688.945 & -2 & 222.342 & 280.470 & 26 & 12.771 .299 & 13.735 .871 & 8 & 42.166 .474 & 46.567 .098 & 10 \\
\hline Sul & 849.693 & 665.767 & -22 & 156.510 & 187.547 & 20 & 13.054 .511 & 11.492 .520 & -12 & 28.726 .492 & 31.382 .790 & 9 \\
\hline Centro-Oeste & 217.022 & 223.275 & 3 & 100.476 & 123.988 & 23 & 9.350 .556 & 9.969 .750 & 7 & 96.000 .530 & 102.034 .572 & 6 \\
\hline
\end{tabular}

Fontes: IBGE (2006; 2017).

Por outro lado, o crescimento das unidades familiares nessas regióes se deu sobre áreas médias um pouco maiores que o "estoque" em 2006: no Norte, a área média das unidades familiares acrescidas (relação entre o número de estabelecimentos acrescidos e o total de área incorporada pela agricultura familiar) foi de 46,5 ha, mas, no Centro-Oeste, esta área média dos "novos" estabelecimentos familiares foi de 99 ha. Como, em todo caso, o crescimento da agricultura familiar foi modesto, esse aumento teve pouco impacto, porém positivo, no aumento da área média dos estabelecimentos familiares nessas regióes entre 2006 e 2017: de 40,2 ha para 41,1 ha, no Norte, e de 43,1 ha para 44,6 ha, no Centro-Oeste. Esses dados são válidos para demostrar que, nas regiôes onde a agricultura familiar cresceu, esse crescimento se deu por meio de estabelecimentos de porte um pouco maior.

Se parece provável a hipótese de que, com redução do número de estabelecimentos dentro da mesma área total, houve concentração no universo da agricultura familiar, as dinâmicas fundiárias dos estabelecimentos agrícolas familiares no Norte e no Centro-Oeste são uma chave de investigação importante para a compreensão desse processo.

Em contrapartida, nas regióes Nordeste e Sul, redutos históricos consolidados da agricultura familiar, os estabelecimentos agrícolas familiares tiveram queda de $16 \%$ e $22 \%$, quanto ao número, e de $8 \%$ e $12 \%$, quanto à área, respectivamente. Todavia, os dados dessas regióes parecem conter indícios importantes para qualificar, de modo mais próximo, outros elementos envolvidos nessa retração da agricultura familiar.

Ora, entre os dois censos, a agricultura familiar perdeu em torno de 469,0 mil estabelecimentos: essa perda explica-se basicamente pela variação negativa do número de estabelecimentos familiares nordestinos - 348,3 mil a menos - e sulistas - 184 mil a menos -, com a perda pequena no Sudeste e a compensaçáo parcial no Norte e no Centro-Oeste dando contorno final aos números. No entanto, ainda na tabela 2, os dados fundiários da agricultura não familiar no Nordeste apontam para outra dimensão da questão. A agricultura não familiar no Nordeste cresceu $81 \%$ em número de estabelecimentos, mas teve uma perda de $6 \%$ de área total. Com isso, a área média desses estabelecimentos, na região, caiu de 179,0 para 93,0 ha. Isto pode significar que o crescimento do 
número de estabelecimentos não familiares e a redução do número de estabelecimentos familiares na região estão relacionados de tal forma que, reiterando a hipótese colocada nas seçôes anteriores, em vez de uma reconcentração ou um reagrupamento de unidades familiares pequenas em unidades patronais maiores, o que parece ter havido foi uma reclassificação de estabelecimentos familiares em estabelecimentos não familiares. Ou seja: um conjunto significativo de estabelecimentos familiares nordestinos, registrados como tais no Censo 2006, mudou de categoria no de 2017, por deixarem de atender a um ou mais dos parâmetros para essa categoria.

Os dados por faixas de área parecem confirmar os indícios levantados nas seções anteriores quanto à perda de estabelecimentos familiares nas faixas de menor área e na classe "produtor sem área”, nas duas regiôes - Nordeste e Sul -, que respondem pela quase totalidade do decréscimo de estabelecimentos familiares entre os levantamentos de 2006 e 2017.

No Nordeste, por exemplo, havia 2,19 milhóes de estabelecimentos familiares em 2006, mas, em 2017, esse total havia caído a 1,84 milhão, uma perda de 348,3 mil estabelecimentos familiares: desse total, 54\% correspondem à perda de quase 188 mil unidades familiares com menos de 20 ha e 37\%, à perda de quase 131 mil unidades familiares do tipo "produtor sem área". Isto significa, portanto, que os estabelecimentos familiares de menos de 20 ha e os "produtores sem área” familiares respondem por mais de $90 \%$ dessa redução. Por outro lado, o número de estabelecimentos não familiares na regiāo quase dobrou, saindo de 267,0 mil para 483,9 mil entre 2006 e 2017: em torno de $90 \%$ do aumento ${ }^{10}$ tocam aos estabelecimentos náo familiares de até 20 ha. Isto sugere que não houve, pura e simplesmente, uma eliminação massiva de unidades familiares ou uma reconcentração destas em unidades maiores, mas, sim, uma mudança de classificação.

$\mathrm{Na}$ região Sul, os processos são parecidos, mas com uma participação bem menor dos produtores sem área. Em 2006, havia 849,7 mil unidades familiares, que se reduziram, em 2017, a 665,8 mil: desta perda de quase 184 mil estabelecimentos familiares, $78 \%$ tocam a unidades de agricultura familiar com menos de 20 ha. Os "produtores sem área" familiares, por sua vez, representam quase $9 \%$ dessa redução. Em contrapartida, os estabelecimentos não familiares na região aumentaram de 156,5 mil para 187,5 mil, e as unidades com menos de 20 ha responderam por $94 \%$ desse aumento. ${ }^{11}$

Como esperado, essas variaçôes negativas repercutem, regionalmente, sobre os totais de pessoal ocupado na agricultura familiar. Os números da tabela 4 expóem essas diferenças: Nordeste e Sul, que, em 2006, respondiam respectivamente por 52\% (5,93 milhôes) e 18\% (2,1 milhóes de trabalhadores) do total de ocupados em unidades familiares, sofreram, em 2017, as mais acentuadas reduçôes de mão de obra: $24 \%$ a menos de ocupados nos estabelecimentos familiares nordestinos e 25\% a menos nos sulistas. Essas duas regiōes registraram, ainda, aumento considerável do pessoal ocupado em estabelecimentos não familiares: $26 \%$ a mais no Nordeste, chegando a 1,62 milhão em 2017, e $8 \%$ a mais no Sul, somando 707,36 mil trabalhadores.

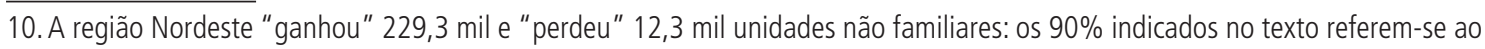
total de acrescidos, não ao "saldo".

11. O Sul "perdeu" 185,6 mil e "ganhou" 1,7 mil unidades familiares: as proporções de 78\% para unidades abaixo de 20 ha e $9 \%$ para produtores sem área referem-se ao total perdido; da mesma forma, a região "ganhou" 35,0 mil unidades não familiares e "perdeu" de 4,0 mil: os 94\% referem-se à participação dos estabelecimentos não familiares de até 20 ha no total acrescido, não no "saldo". 


\section{TABELA 4}

Pessoal ocupado em estabelecimentos agropecuários, por tipologia - Brasil e Grandes Regiões (2006 e 2017)

\begin{tabular}{|c|c|c|c|c|c|c|}
\hline \multirow{3}{*}{$\begin{array}{l}\text { Brasil e Grandes } \\
\text { Regiões }\end{array}$} & \multicolumn{6}{|c|}{ Pessoal ocupado } \\
\hline & \multicolumn{3}{|c|}{ Familiar } & \multicolumn{3}{|c|}{ Não familiar } \\
\hline & 2006 & 2017 & $\begin{array}{c}\text { Variação } \\
(\%)\end{array}$ & 2006 & 2017 & $\begin{array}{c}\text { Variação } \\
(\%)\end{array}$ \\
\hline Brasil & 11.412 .691 & 9.674 .431 & -15 & 4.093 .208 & 4.850 .642 & 19 \\
\hline Norte & 1.195 .747 & 1.421 .443 & 19 & 248.556 & 419.048 & 69 \\
\hline Nordeste & 5.931 .934 & 4.529 .802 & -24 & 1.281 .514 & 1.618 .388 & 26 \\
\hline Sudeste & 1.713 .190 & 1.630 .096 & -5 & 1.453 .322 & 1.491 .854 & 3 \\
\hline Sul & 2.090 .131 & 1.568 .915 & -25 & 652.125 & 707.356 & 8 \\
\hline Centro-Oeste & 481.689 & 524.175 & 9 & 457.691 & 613.996 & 34 \\
\hline
\end{tabular}

Fontes: IBGE (2006; 2017).

Em linhas gerais, a redução de pessoal ocupado em estabelecimentos agrícolas familiares no Nordeste e no Sul responde quase inteiramente pela diminuição da mão de obra na agricultura familiar no país no período intercensitário: somadas, as perdas dessas regióes representam uma redução de 1,92 milhão de ocupados agrícolas familiares (1,4 milhão no Nordeste e 521,2 mil no Sul). Considerando ainda a pequena diminuição de pessoal ocupado na agricultura familiar no Sudeste, o saldo nacional da perda - 1,7 milhão de trabalhadores a menos na agricultura familiar - é um pouco menor, devido ao crescimento de ocupados agrícolas familiares no Norte e no Centro-Oeste. No entanto, em ambas as regióes esse crescimento de ocupados familiares se fez acompanhar de um aumento ainda mais expressivo da mão de obra em unidades náo familiares: $69 \%$ no Norte e 34\% no Centro-Oeste, totalizando, respectivamente, 419,0 e 614,0 mil empregados.

Os dados fundiários dessas duas últimas regióes, vistos há pouco, podem sugerir que a expansão da agricultura familiar nelas, em unidades de porte um pouco maior (sobretudo no Centro-Oeste), náo foi capaz de gerar postos de ocupação em número suficiente para rebater a perda de ocupados nas regióes tradicionais.

A princípio, pois, os resultados reiteram a hipótese de que a variação do total de pessoas ocupadas na agricultura familiar acompanha, nas regiōes, a variação do total de estabelecimentos agrícolas familiares, crescendo onde estes crescem e diminuindo onde estes diminuem. Como o crescimento do pessoal ocupado na agricultura familiar no Norte e no Centro-Oeste se fez acompanhar de um crescimento ainda mais expressivo, nessas regióes, dos ocupados em estabelecimentos agropecuários, é possível que esse movimento se relacione mais à dinâmica da fronteira agrícola, subordinada à expansão da agricultura patronal, que a uma dinâmica intrínseca de consolidação da agricultura familiar naquelas regióes.

Em reforço à hipótese que vem sendo desenvolvida até aqui, os dados das tabelas 5 e 6 , que representam, nas primeiras colunas de cada ano, o percentual de pessoal ocupado por 
grupos de área, e, nas segundas e terceiras colunas, a divisão do total de ocupados por grupos de área em estabelecimentos familiares e não familiares, em 2006 e 2017, nas regiôes Nordeste (tabela 5) e Sul (tabela 6), reiteram dois pontos importantes. Em primeiro lugar, a distribuição geral de ocupados por grupos de área (primeira coluna de cada ano) pouco se alterou entre 2006 e 2017; em contrapartida, em segundo lugar, a participação da agricultura familiar no total de ocupados caiu significativamente nos estabelecimentos de até 20 ha, com crescimento inversamente proporcional da participaçáo das unidades não familiares.

TABELA 5

Pessoal ocupado por grupos de área e percentual de pessoal ocupado em estabelecimentos familiares e não familiares por grupos de área - Região Nordeste (2006 e 2017)

(Em \%)

\begin{tabular}{|c|c|c|c|c|c|c|}
\hline \multirow{2}{*}{ Grupos de área } & \multicolumn{3}{|c|}{2006} & \multicolumn{3}{|c|}{2017} \\
\hline & Total & Não familiar & Familiar & Total & Não familiar & Familiar \\
\hline Mais de 0 a menos de 1 ha & 15 & 7 & 93 & 16 & 23 & 77 \\
\hline De 1 a menos de 5 ha & 28 & 8 & 92 & 31 & 19 & 81 \\
\hline De 5 a menos de 10 ha & 11 & 10 & 90 & 12 & 18 & 82 \\
\hline De 10 a menos de 20 ha & 10 & 12 & 88 & 11 & 18 & 82 \\
\hline De 20 a menos de 50 ha & 13 & 16 & 84 & 13 & 19 & 81 \\
\hline De 50 a menos de 100 ha & 6 & 25 & 75 & 6 & 26 & 74 \\
\hline De 100 a menos de 200 ha & 4 & 45 & 55 & 3 & 45 & 55 \\
\hline De 200 a menos de 500 ha & 3 & 84 & 16 & 3 & 85 & 15 \\
\hline De 500 a menos de 1.000 ha & 1 & 98 & 2 & 1 & 100 & 0 \\
\hline Mais de 1.000 ha & 2 & 99 & 1 & 3 & 100 & 0 \\
\hline Produtor sem área & 6 & 5 & 95 & 1 & 18 & 82 \\
\hline Total & 100 & 18 & 82 & 100 & 26 & 74 \\
\hline
\end{tabular}

Fontes: IBGE (2006; 2017).

$\mathrm{Na}$ região Nordeste, como se vê, a escala das proporçóes manteve-se praticamente constante, com ligeiro amento de pessoal ocupado entre os estabelecimentos até 20 ha: estes que, em 2006, absorviam, ao todo, 64\% dos ocupados, passaram a concentrar 70\% deles em 2017 . No entanto, as proporções de ocupados e unidades não familiares subiram significativamente (segundas colunas de cada ano) nas faixas menores de área: nos estabelecimentos de até 1 ha, o percentual aumentou de 7\%, em 2006, para 23\%, em 2017; nas unidades de 1 a 5 ha, o salto foi de $8 \%$ para $19 \%$. Nessas duas faixas, a representação relativa dos estabelecimentos familiares (terceiras colunas) caiu de $93 \%$ para $77 \%$ e de $92 \%$ para $81 \%$, respectivamente. Nos estabelecimentos de 5 a 10 ha e de 10 a 20 ha o processo se repetiu, conforme pode ser observado. 
TABELA 6

Pessoal ocupado por grupos de área e percentual de pessoal ocupado em estabelecimentos familiares e não familiares por grupos de área - Região Sul (2006 e 2017)

$($ Em \%)

\begin{tabular}{|c|c|c|c|c|c|c|}
\hline \multirow{2}{*}{ Grupos de área } & \multicolumn{3}{|c|}{2006} & \multicolumn{3}{|c|}{2017} \\
\hline & Total & Não familiar & Familiar & Total & Não familiar & Familiar \\
\hline Mais de 0 a menos de 1 ha & 3 & 13 & 87 & 3 & 34 & 66 \\
\hline De 1 a menos de 5 ha & 15 & 11 & 89 & 15 & 22 & 78 \\
\hline De 5 a menos de 10 ha & 16 & 9 & 91 & 15 & 15 & 85 \\
\hline De 10 a menos de 20 ha & 24 & 9 & 91 & 22 & 11 & 89 \\
\hline De 20 a menos de 50 ha & 21 & 13 & 87 & 21 & 13 & 87 \\
\hline De 50 a menos de 100 ha & 7 & 47 & 53 & 8 & 43 & 57 \\
\hline De 100 a menos de 200 ha & 4 & 96 & 4 & 5 & 95 & 5 \\
\hline De 200 a menos de 500 ha & 4 & 100 & 0 & 4 & 100 & 0 \\
\hline De 500 a menos de 1.000 ha & 2 & 95 & 5 & 2 & 100 & 0 \\
\hline Mais de 1.000 ha & 3 & 99 & 1 & 5 & 100 & 0 \\
\hline Produtor sem área & 2 & 10 & 90 & 0 & 29 & 71 \\
\hline Total & 100 & 24 & 76 & 100 & 31 & 69 \\
\hline
\end{tabular}

Fontes: IBGE (2006; 2017).

Na região Sul, verifica-se algo ligeiramente diferente - os estabelecimentos de até 20 ha passaram a absorver $54 \%$ dos ocupados em 2017, contra 58\% em 2006 -, mas que não altera o sentido geral do movimento: nos estabelecimentos não familiares de até 1 ha, o percentual aumentou de 13\%, em 2006, para 34\%, em 2017; nas unidades não familiares de 1 a 5 ha, o salto foi de $11 \%$ para $22 \%$. Em ambas as faixas, a participação relativa dos estabelecimentos familiares caiu de $87 \%$ para $66 \%$ e de $89 \%$ para $78 \%$, respectivamente. Nas unidades de 5 a 10 ha e de 10 a 20 ha, ainda que menos acentuadamente, a mesma tendência pode ser notada.

Portanto, embora sejam regióes de presença tradicional da agricultura familiar, Nordeste e Sul oferecem paisagens agrícolas distintas e estruturas agrárias e produtivas diferentes. No entanto, esse pequeno aprofundamento na análise dos dados de pessoas ocupadas nos estabelecimentos familiares dessas regióes, mesmo sem franquear uma leitura das mudanças qualitativas entre os censos, permite identificar um padrão quantitativo que ajuda a compreender parte das razóes da redução da agricultura familiar entre os censos.

\section{CONSIDERAÇÕES FINAIS}

Os dados relativos à variação do pessoal ocupado por laços de parentesco e por região - Nordeste e Sul, sobretudo -, segundo os grupos de área, reforçam, em boa medida, as conclusóes preliminares levantadas neste texto. 
De modo geral, portanto, a perda do número de estabelecimentos familiares e a redução do pessoal ocupado na agricultura familiar são processos associados e se mostraram mais intensos nos estabelecimentos de menor área (até $20 \mathrm{ha}$ ) e nas regióes tradicionais da agricultura familiar, Nordeste e Sul. Uma vez que não houve, aparentemente, variação significativa na distribuição do número de estabelecimentos e do total de pessoal ocupado por grupos de área nem considerando as regióes, nem considerando os laços de parentesco -, a perda de unidades familiares e o aumento de unidades nấo familiares na faixa de até 20 ha pareceu corresponder a uma reclassificaçáo de um contingente de estabelecimentos agropecuários identificados em 2006 como familiares, mas que, em 2017, não cumpriam todos os parâmetros necessários para manterem esse status. Além disso, conforme foi mencionado sucessivamente no texto, boa parte da "perda" da agricultura familiar entre os censos se deve à revisão metodológica da categoria "produtor sem área".

Dentro dos limites deste estudo, a leitura regional dos dados da agricultura familiar náo permite, é claro, avançar sobre as mudanças de matriz produtiva ou técnica que poderiam estar por trás dessa redução do pessoal ocupado - como o aumento da mecanização e do uso de insumos químicos nos estabelecimentos familiares, por exemplo $-{ }^{12}$ mas oferece uma chave de interpretação um pouco mais apurada para a compreensáo do processo associado de reduçáo de estabelecimentos e de pessoas ocupadas na agricultura familiar.

\section{REFERÊNCIAS}

IBGE - INSTITUTO BRASILEIRO DE GEOGRAFIA E ESTATÍSTICA. Censo Agropecuário 2006. Rio de Janeiro: IBGE, 2006.

Censo Agropecuário 2017. Rio de Janeiro: IBGE, 2017. Disponível em: <https:// tinyurl.com/y8l2yd5e>.

DELGROSSI, M. E. Algoritmo para delimitação da agricultura familiar no Censo Agropecuário 2017, visando a inclusáo de variável no banco de dados do censo, disponível para ampla consulta. Brasília: FAO; SAF/Mapa; Finatec, 2019. Disponível em: <https:// tinyurl.com/y2xz9oh2>. 